\title{
2006-252: ENGAGING TEACHERS AND STUDENTS IN PROBLEM BASED SIMULATION ACTIVITIES
}

\section{John Irwin, Mott Community College}

Dr. John Irwin has presented at the ASEE conference once before in 2002 in the Engineering Technology area. Presently Dr. Irwin is a Professor of Design Engineering Technology at Mott Community College, Flint, Michigan. He has earned a Master's degree in Occupational Education from Ferris State University, Big Rapids, Michigan and a Doctorate in Curriculum \& Instruction from Wayne State University, Detroit, Michigan. Dr. Irwin has also been a Program Manager for a National Science Foundation grant awarded in the area of Advanced Technology Education from 2002 - present.

\section{James Moseley, Wayne State University}

Dr. James Moseley holds the position of Associate Professor - Department of Community Medicine, Wayne State University, Detroit, Michigan. He has earned Master's degrees in Guidance \& Counseling, Medical Bibliography, Instructional Technology, and Health Services as well as a Specialist degree in Student Personnel Work and a Doctorate in Secondary Curriculum Development. Dr. Moseley has published numerous articles, book chapters and textbooks over the years, most recently in 2004 in the area of Performance Technology. 


\title{
Engaging Teachers and Students in Problem-based Simulation Activities
}

\begin{abstract}
This study investigates the perceptions of teachers and students involved in problembased simulation, (PBS) activities used in design engineering curricula to introduce simulation as a design tool to better evaluate design solutions. The presentation demonstrates a clear and concise interpretation of the teacher and students developmental perceptions of the curricula developed at Mott Community College through a grant from NSF to enhance existing design engineering curricula using PBS activities. Through this study it is evident that the PBS activities have enhanced the curricula by providing a tool for students to better understand design concepts. It is also evident, that teachers and students learned to value and trust using simulation software as a beneficial teaching and learning tool to evaluate and validate their own design solutions.
\end{abstract}

The criteria used to determine participant inclusion and sample size is based on the research primarily being a qualitative study in which a relatively small sample size of three school settings have been chosen to test the curriculum. Each of the three schools included at least two of their classes in the study teaching topics of gears, cams and threads in their design engineering classes. One class was a control group that received traditional methods of instruction and the other was the treatment group which participated in the PBS activities.

The study was conducted using a quasi-experimental post-test only design as a quantitative component, and a qualitative component comparing prior and post surveys and observations. The curriculum materials produced through the NSF grant are PBS activities related to topics of gears, cams and threads which provide problems for the students to solve using reference material, which they then verify using a CAD generated $3 \mathrm{D}$ model that simulates the solution to the problem. The output from the $3 \mathrm{D}$ simulation is in the form of a plotted curve on a graph providing the answer to the problem and also providing a 3D motion output for a virtual visualization of the problem.

Workshops are scheduled for May through July of 2006 to orient teachers how to utilize the design and simulation software used in the delivery of the PBS activities. After completing the workshops instructors possess the skills and curriculum to deliver summer recruitment camps or teach the topics of gears, cams and threads in their engineering technology classes using the 3D models of mechanisms and simulations.

Introduction

Simulation of the dynamics of mechanisms used in engineering technology curricula is presently a new concept rarely studied and there is a lack of understanding of how such simulations can be used most effectively in engineering and in education. The following is a quasi-experimental action research study incorporating both quantitative and qualitative data. It investigates the perceptions of teachers and students involved in problem-based simulation activities used in high school design engineering curricula. 
The purpose of this research is to investigate the potential for problem-based simulation activities to be used as curriculum and instruction aids for engineering educators.

The research problem statement is to investigate the perceptions of teachers and students involved in problem-based simulation activities used in high school design engineering curriculum to introduce simulation as a design tool to better evaluate design solutions. There are three main objectives of this study. Firstly, to document the achievement level of one group of technology high school students using the problem-based simulation activities compared to another group using traditional methods of instruction. Secondly, to document, narrate, and interpret technology teachers' developmental perceptions of the educational effectiveness of using problem-based simulation activities in their lesson plans. And lastly, to document, narrate, and interpret the nature of classroom interactions and discourse when technology teachers use problem-based simulation activities?

Simulation in Education

Research tells us that learning activities which recreate work situations foster better transfer of learning (Swanson \& Holton, 1999) ${ }^{9}$. Games and simulations have been used in education as useful learning tools for years, although computer-based simulations in education have recently been increasingly utilized due to the increased presence of desktop computers and technology in classrooms. Simulation is defined as a representation of the operation or features of one process or system through the use of another; for example, the computer simulation of an in-flight emergency (Hill \& Semler, $2001)^{5}$. Long before computer simulation was possible John Dewey (1916) ${ }^{4}$, advocated an educational system with continued experimentation and vocational training to equip students to solve practical problems. Through the process of experimentation, application of theoretical concepts to the simulated environment and feedback providing important insights impossible through other learning methods, simulations have been proven to enhance the learner's ability to make quick progress in skill development.

\section{Problem-based Learning}

In problem-based approaches, students clearly define the problem, develop hypotheses, gather information, and arrive at a clearly stated solution, (Allen, 1998) ${ }^{2}$. The problembased activities used in this study are intended to introduce the students to concepts of gears, cams and threads using simulations which offer the students the opportunity to predict results and analyze their predictions while they are also presented information about how to create the drawings and models of these types of parts. For instance, the high schools in this study that include the topic of threads in their curricula traditionally have students create drawings of different thread types and forms, but have not emphasized the effect of thread forms as related to torque or part travel. In problembased learning (PBL) students are presented with an interesting, relevant problem "up front", so that they can acquire knowledge in the context in which it will be used and be more likely to retain what they learned (Albanese and Mitchell, 1993; Boud and Folletti, $1991)^{1,3}$. PBL comes in many forms including research, case studies, guided design, design projects, and the McMaster Medical School model of PBL. The problem-based activities used in this study are not intended to be semester long projects to be researched or studied, but rather they are smaller in content involving a student or students 
predicting a result to a given scenario and then verifying the prediction using the simulation software over the period of two or three class meetings.

By utilizing simulations in PBL curricula students can be placed in environments that present dilemmas that can be addressed in a variety of different ways. It is through struggling with issues and solutions to problems that cognitive, affective, and moral growth occurs (Kohlberg, 1979; Piaget, 1963) ${ }^{7,8}$. The PBL activities in and of themselves are not the answer to applying the theories related in this research. Cognitive structuralists and cognitive scientists use developmental psychology, which is the educational basis of PBL. The main supporters of the cognitive theories are Jean Piaget and Robert Gagne. The implementation of the PBL activities involves instructor guidance, reflection and motivation as well. Constructivism is an off chute from cognitivism where theorists believe not all information is known and there isn't necessarily one truth to all questions. Constructivist philosophy believes knowledge is based on experiences and one must construct their own meanings. John Dewey, born out of a progressive philosophy, believes in social constructivist psychology, because he is concerned with the process rather than the end product of the curriculum (Dewey, 1916) ${ }^{4}$.

Cognitive teaching involves problem solving, cooperative learning and discovery learning, where the teacher is a facilitator of information rather than a deliverer of information. The moment when the student is in need of information is where the teacher will guide the student towards the intended outcomes. There is empirical proof that cooperative learning methods are more effective methods than straight lecture formats, where students are actively involved in problem solving activities rather than passively accepting what is being lectured to them, (Johnson, D.W. et al., 1981) ${ }^{6}$. The methods used in cooperative learning are not fully understood and are out of the comfort zone of many instructors who feel that they are not in control of the classroom in an active learning environment.

Content and Context of the Study

This research is related to the products developed through a National Science Foundation (NSF) Grant to integrate simulation into Design Engineering Technology (DET) associate degree programs. NSF funded the development of Tech Prep/Associate Degree activities that focus on 3D CAD model simulations developed in the State of Michigan by Mott Community College (MCC), in cooperation with Henry Ford, Macomb and Oakland Community Colleges and their K-12 partners. Specifically, the deliverables of the NSF grant are ten modules that can be integrated into the community college Design/CAD curriculum. These modules introduce simulation as a robust design tool that can be used to better evaluate design solutions.

The three modules developed for threads, gears and cams were chosen for this study because they were the first three developed and they are most applicable to high school students. The design of the threads, cams and gears simulation activities allow the learners to engage in the activity and to progress to the next step at their own pace. If the learners solve a problem incorrectly they can run the simulation results over and over until they understand the concept. The simulation activities were developed using the 
Autodesk Inventor software for the 3D models and the MSC Software Dynamic Designer product for the motion analysis. The Worldwide Instructional Design System (WIDS) was used as the curriculum design tool.

The subjects shown in Table 1 are teachers and students at three high schools in Genesee County, Michigan, which is the service area for MCC, and these schools participate in articulation agreements with the DET department at MCC. All three of the high school classes chosen for this study have similar descriptions and require similar experience and prerequisite skills. Although, shown in Figure 1 the students from School C, who make up about $40 \%$ of the comparison group, have not had any previous drafting background, where students from Schools A and B have had at least one year of drafting experience. The instructors are vocationally certified ensuring that they have at least 4000 hours of relevant work experience in the mechanical engineering industry.

Table 1

Student Comparison and Treatment Group Demographics

\begin{tabular}{|c|c|c|c|c|c|c|c|c|}
\hline & \multirow{2}{*}{$\begin{array}{l}\text { School A } \\
\text { Treatment } \\
\text { Group }\end{array}$} & \multicolumn{2}{|c|}{ School B } & \multicolumn{3}{|c|}{ School C } & \multicolumn{2}{|c|}{ Totals } \\
\hline & & $\begin{array}{l}\text { Treatment } \\
\text { Group }\end{array}$ & $\begin{array}{l}\text { Compare } \\
\text { Group }\end{array}$ & $\begin{array}{l}\text { Treatment } \\
\text { Group }\end{array}$ & $\begin{array}{l}\text { Compare } \\
\text { Group }\end{array}$ & $\begin{array}{l}\text { Compare } \\
\text { Group }\end{array}$ & $\begin{array}{l}\text { Treatment } \\
\text { Group }\end{array}$ & $\begin{array}{l}\text { Compare } \\
\text { Group }\end{array}$ \\
\hline $\begin{array}{l}\text { Total number of } \\
\text { Students }\end{array}$ & 23 & 20 & 20 & 21 & 21 & 24 & 64 & 65 \\
\hline $\begin{array}{l}\text { Female } \\
\text { Students }\end{array}$ & 2 & 2 & 2 & 3 & 2 & 3 & 7 & 7 \\
\hline Male Students & 21 & 18 & 18 & 18 & 19 & 21 & 57 & 58 \\
\hline $\begin{array}{l}\text { Students Grade } \\
\text { Level - } 9\end{array}$ & 1 & 0 & 0 & 11 & 11 & 13 & 12 & 24 \\
\hline $\begin{array}{l}\text { Students Grade } \\
\text { Level - } 10\end{array}$ & 3 & 10 & 8 & 5 & 7 & 7 & 18 & 22 \\
\hline $\begin{array}{l}\text { Students Grade } \\
\text { Level - } 11\end{array}$ & 9 & 7 & 11 & 2 & 2 & 1 & 18 & 14 \\
\hline $\begin{array}{l}\text { Students Grade } \\
\text { Level - } 12\end{array}$ & 10 & 3 & 1 & 3 & 1 & 3 & 16 & 5 \\
\hline $\begin{array}{l}\text { First year in } \\
\text { Drafting }\end{array}$ & 0 & 0 & 0 & 21 & 21 & 24 & 21 & 45 \\
\hline $\begin{array}{l}\text { Second year in } \\
\text { Drafting }\end{array}$ & 18 & 20 & 20 & 0 & 0 & 0 & 38 & 20 \\
\hline $\begin{array}{l}\text { Third year in } \\
\text { Drafting }\end{array}$ & 5 & 0 & 0 & 0 & 0 & 0 & 5 & 0 \\
\hline
\end{tabular}

Figure 1 - Research Sample Experience Comparison 


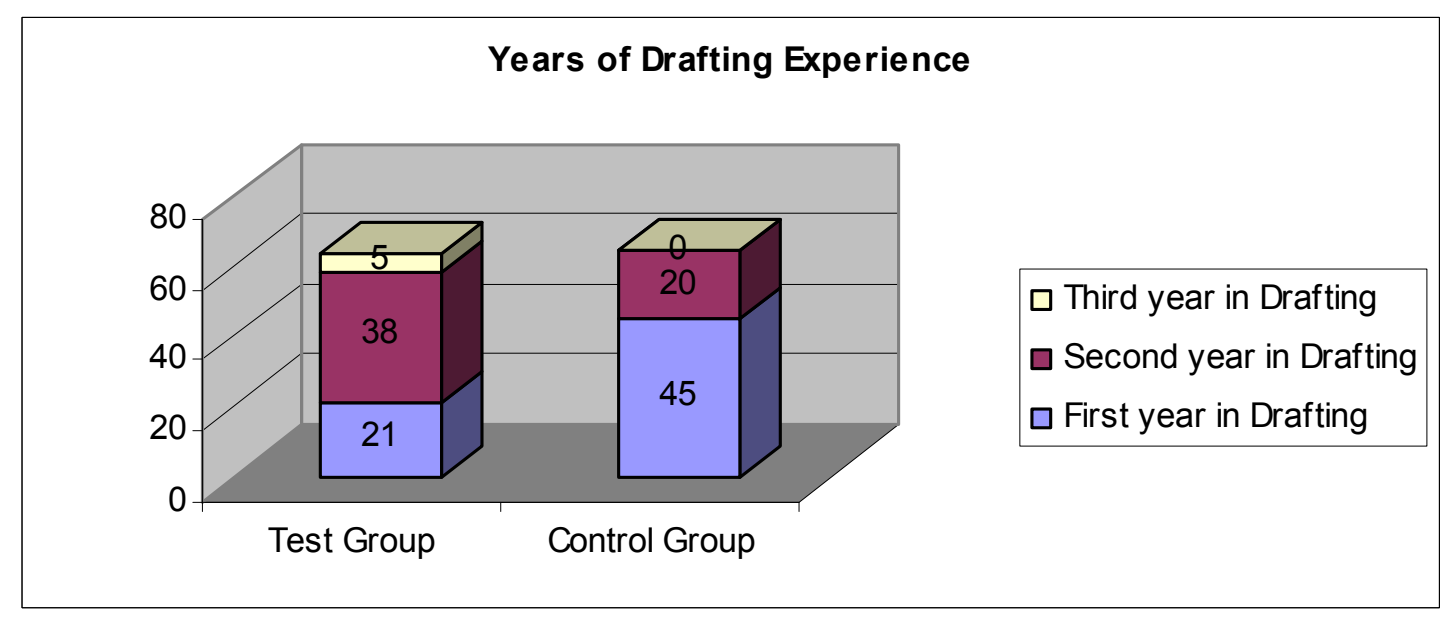

Research Design Methodology

The design structure for the quantitative research is quasi-experimental because of the lack of true randomization. The design involves assignment of two groups of subjects from the accessible population; one group from one school will get the intervention, (the simulation activities) and the comparison group will get the usual intervention, (the standard curriculum). Observations will be conducted at the conclusion of each unit of intervention using a standard post-test instrument. The post-test only design is used because the subject matter being taught is new information that students in the study have not been exposed to in the past so they need not be tested on their prior knowledge of the material.

The design for the qualitative research involves individual teacher and student survey questions and classroom observations of three teachers who will use the simulation activities in their classrooms. Prior to teaching their courses in CAD/Drafting, the teachers were trained to effectively use the software and present the problem-based simulation activities. Then, the instructors were surveyed for their perceptions of the problem based simulation activities prior to using them in their lessons.

Data Collection and Analysis Methodology

The post-test scores for each unit taught were recorded for each student in the comparison and treatment group and entered anonymously into a table of scores for that group. The post-test is the standard test used by the MCC DET department as an assessment tool for the units of curriculum being taught. The DET department uses the test to evaluate students who wish to test out of a class for high school or work experience articulation purposes. The post-test consists of multiple choice written questions, short answer, and performance sections. Performance CAD modeling assessments were not used in this study, because the performance involves a very time intensive CAD project for which the high school students were not sufficiently prepared.

The surveys were transcribed and coded for common themes. Answers to questions were entered into tally sheets showing the textual content as well as a summary of the material. The method used to code the material was to input the data into the computer program 
QSR N6. The researchers believe there is an advantage to using charts and matrixes to visualize the data in order to make sense out of pages of text. They utilize techniques such as concept ordered displays of the data according to perceptions of teachers and students over the period of the study.

The null hypothesis is that there is no difference in the two groups in terms of the students' performance on the post-test. A non-parametric test is conducted, because there is no reason to believe that the scores will be normally distributed. The analysis of the post-test scores is performed using the Wilcoxon Rank-Sum Test, because of the hypothesis of differences in average performance. The results of the teacher and student surveys of prior perceptions are compared to surveys of teacher and student post perceptions for the extracting of related themes, topics or issues using QSR N6 qualitative statistical software package. This categorized material is used to create descriptive accounts of the participants' perceptions before and after using the simulation activities.

Results

The study was conducted over a two-month period from March through April of 2005. Each school had a different approach to the integration of the activities into their regular schedule of high school functions including MEAP testing and spring break. Figure 2 represents the amount of time allotted to teaching the topics of cams, gears and threads for the comparison and treatment groups of students at the individual schools.

Figure 2 - Classroom time using PBL Simulation Activities

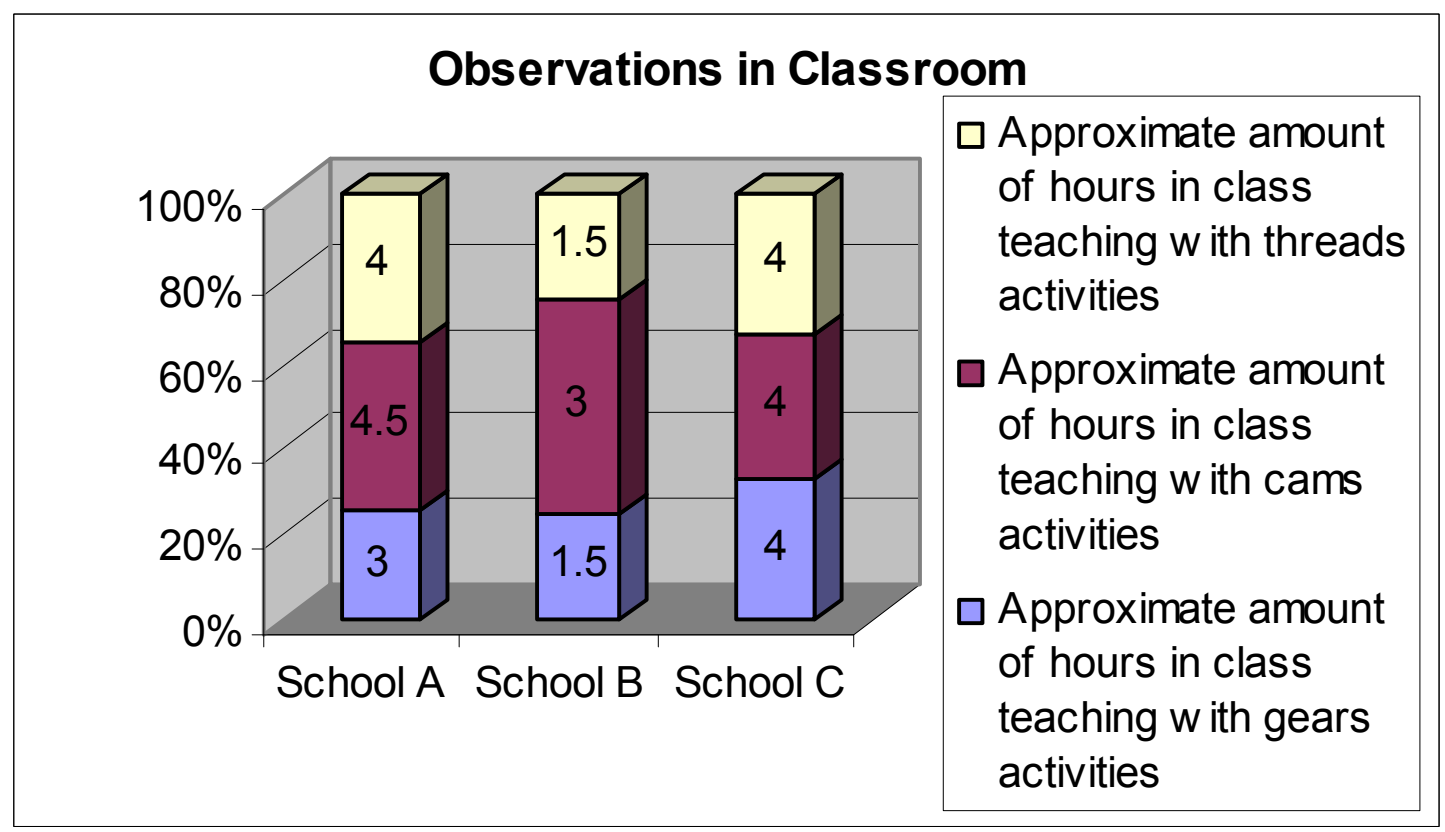

To document the nature of classroom interactions and discourse when simulations were used in problem-based learning activities, observations of students and teacher interactions are shown in Figures 3-5. Observations were charted on a scale of 1-5, with 1 defined as unsatisfactory and 5 being excellent. Observations were categorized in three 
categories: Student Observations - maximum score $=75$, Classroom Commitment maximum score $=20$, Teacher Observations - maximum score $=95$. The reactions were averaged for each school from three separate recording sessions, one during the teaching of each unit of instruction on threads, gears and cams. It was most difficult to objectively rate Schools $\mathrm{B}$ and $\mathrm{C}$, because the primary researcher was more active in assisting the instructor for most of the class period than at School A. The instructor at School A was the most prepared to teach the topics because of prior experience and preparation with the simulations before the classroom session started, so the primary researcher mostly observed rather than assisted with instruction.

Figure 3 - Student Interaction Observations

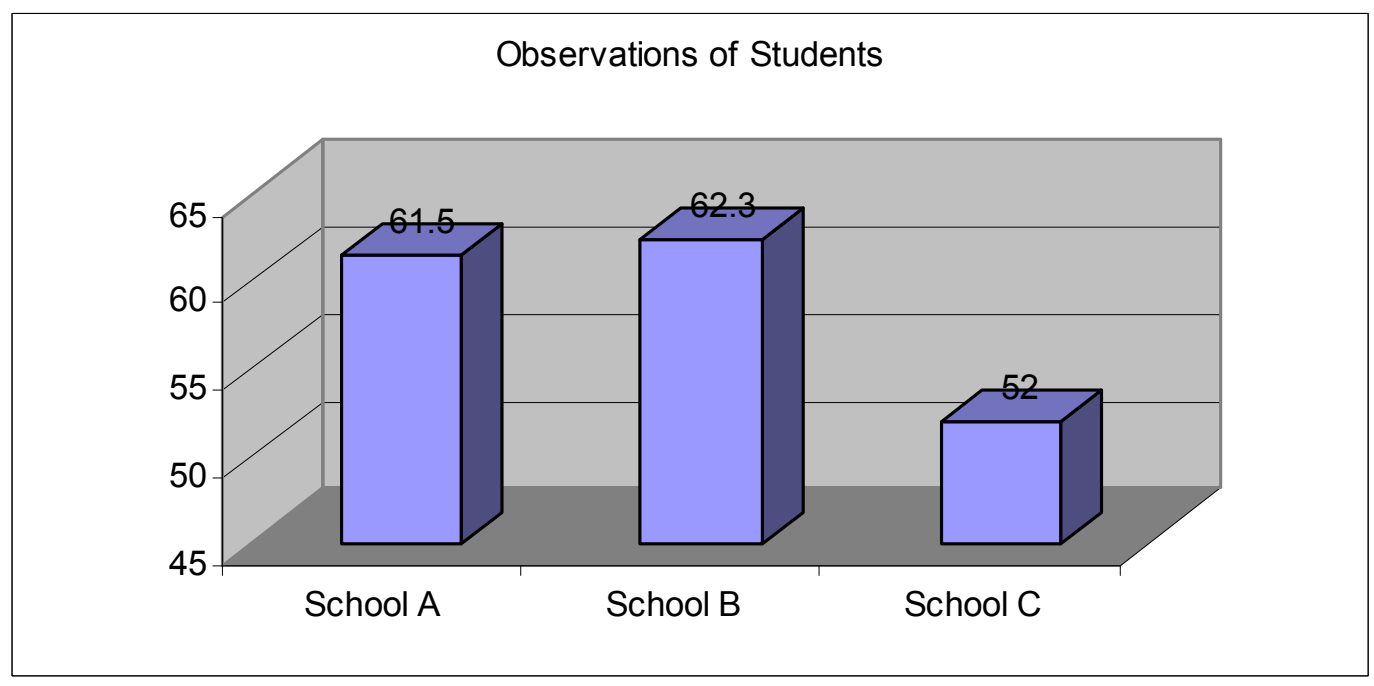

Figure 4 - Classroom Commitment Observations

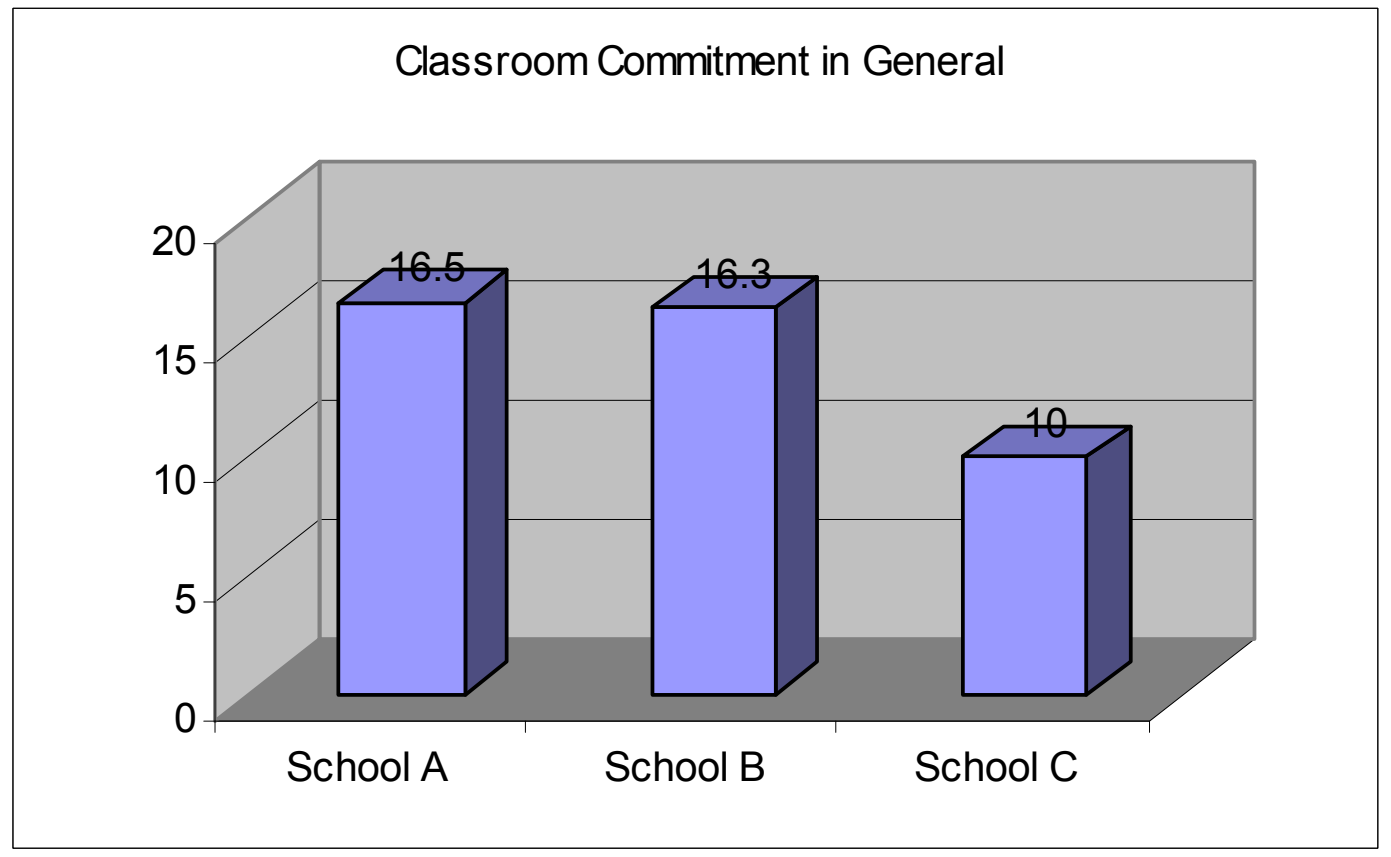


Figure 5 - Teacher Interaction Observations

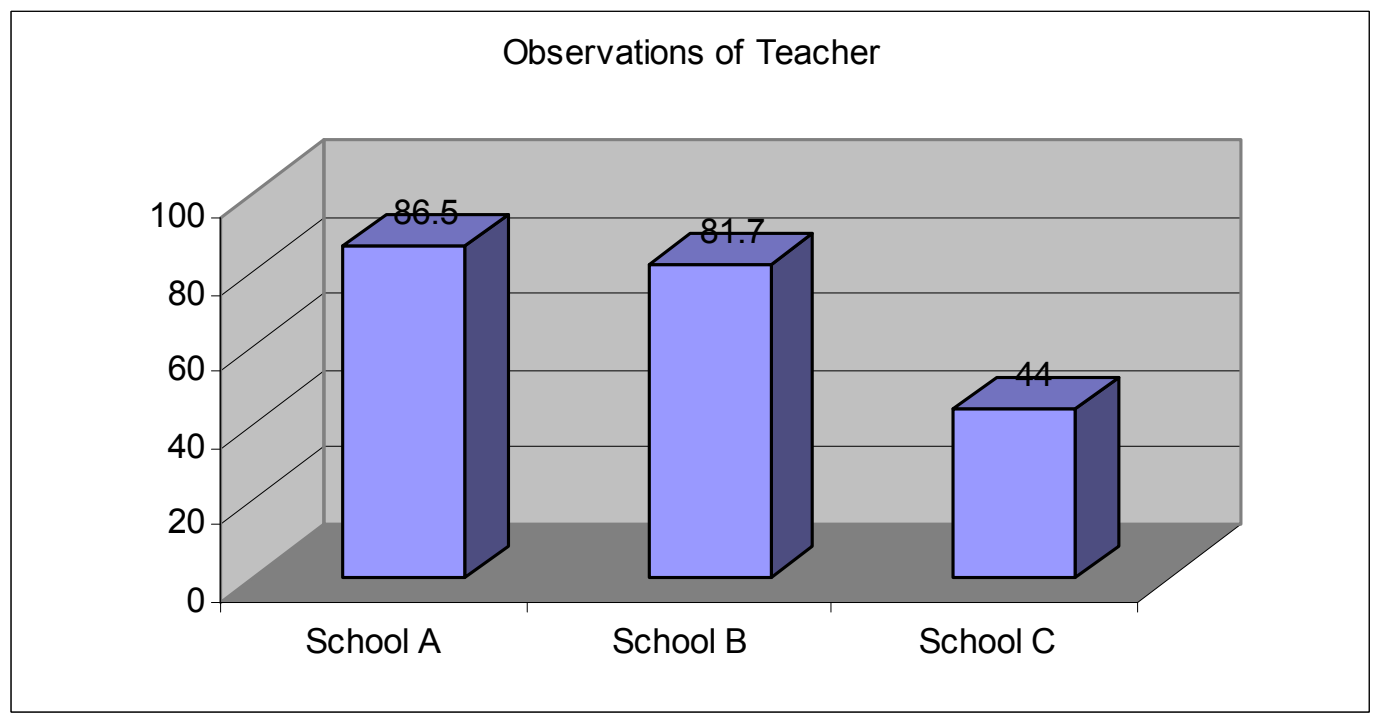

Quantitative results

After the students in the treatment groups were given the intervention (the simulation activities for the units of cams, gears and threads) they were tested for their knowledge along with the control group, which had been taught the same topics without the simulation activities. The traditional methods differed in comparison between Schools A, $\mathrm{B}$ and $\mathrm{C}$, but generally included doing the thread, gear and cam calculations using written problems and 2D drawing diagrams. Some of the students created 2D drawings of gears, cams, and threads and also did activities involving looking at real gears, cams, and threads on machines and mechanisms.

Ideally both the treatment and comparison groups would have the same traditional activities and the simulations would be a supplement, but because of time restrictions all of the schools used the simulation activities as a substitute and the treatment group did not have time to do any drawing projects of gears, cams and threads before the post tests. Table 2 represents the post test results as group average scores, and also communicates the Wilcoxon statistics, standard deviation of the comparison group and the effect size while Figure 6 illustrates the post test score comparisons as percentages.

Table 2 - Post Test results

\begin{tabular}{|l|r|r|r|}
\hline Schools A, B \& C & \multicolumn{1}{l|}{ Threads } & \multicolumn{1}{l|}{ lams } & \multicolumn{1}{l|}{ Gears } \\
\hline Possible points & 6 & 15 & 17 \\
\hline Treatment group average & 3.8667 & 10.6774 & 11.7167 \\
\hline Comparison group average & 2.3846 & 8.3934 & 9.3016 \\
\hline Wilcoxon Rank Sum Z & 2.25 & 4.03 & 2.97 \\
\hline $\begin{array}{l}\text { Standard deviation } \\
\text { comparison group }\end{array}$ & 2.17 & 3.06 & 4.59 \\
\hline Effect Size & .68 & .75 & .53 \\
\hline
\end{tabular}


Figure 6 - Post Test Percentages

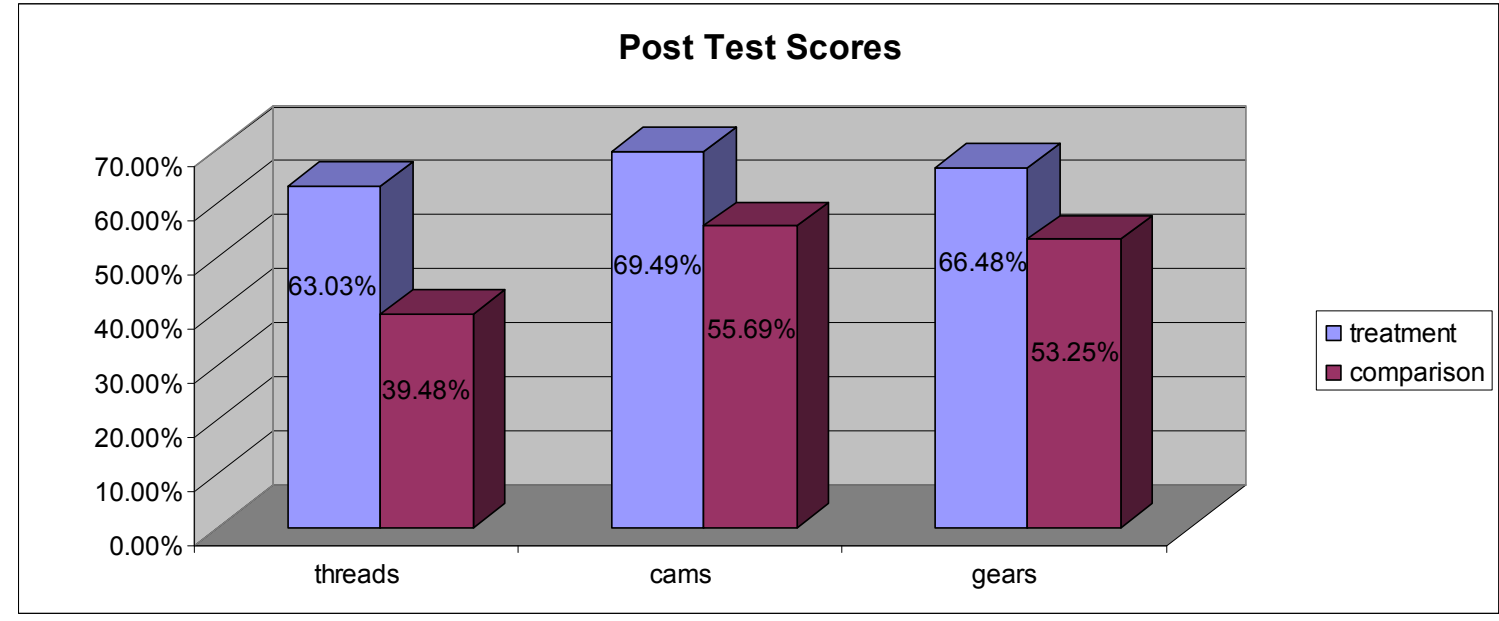

Qualitative results

The nature of teacher developmental perceptions from prior to post teaching perceptions of the integration of problem-based simulation activities was basically unchanged throughout the study. The teachers were asked several of the same questions in the prior and post surveys with the difference being that prior to teaching the material they had reviewed the curriculum, and were asked to predict the curricula effectiveness. After actually teaching with the materials the teacher answers to similar questions were mainly unchanged except for the curriculum usefulness. The results of the coding of developmental perceptions are related in Table 3 summarized in the topics of Curriculum usefulness, Educational effectiveness, Modifications necessary, and Advantages of simulation activities, which were compared from prior to post teaching.

Table 3 - Teacher Developmental Perceptions

\begin{tabular}{|c|c|c|c|}
\hline \multirow{2}{*}{ Survey Topics } & \multicolumn{2}{|c|}{ Evidenced by } & $\begin{array}{c}\text { Nature of } \\
\text { Developmental } \\
\text { Perceptions }\end{array}$ \\
\cline { 2 - 4 } & Prior Perceptions & Post Perceptions & $\begin{array}{c}\text { Changed - } \\
\text { Concern with } \\
\text { method of } \\
\text { delivery of } \\
\text { materials }\end{array}$ \\
\hline Curriculum Usefulness & $\begin{array}{c}\text { "Useful", "Very Useful", } \\
\text { "Great", "Yes", "Help a } \\
\text { lot", "Very helpful" }\end{array}$ & $\begin{array}{c}\text { "Most followed along", } \\
\text { "They should have } \\
\text { received more } \\
\text { background", "Pretty user } \\
\text { friendly", "Ran through } \\
\text { materials too fast" }\end{array}$ & No change \\
\hline $\begin{array}{c}\text { Educational } \\
\text { Effectiveness }\end{array}$ & $\begin{array}{c}\text { "Good", "Good", } \\
\text { "Excellent" }\end{array}$ & $\begin{array}{c}\text { "Good", "Good", } \\
\text { "Excellent" }\end{array}$ & No change \\
\hline $\begin{array}{c}\text { Modifications } \\
\text { Necessary }\end{array}$ & $\begin{array}{c}\text { "Application Exercises", } \\
\text { "Presentations" }\end{array}$ & $\begin{array}{c}\text { "Application Exercises", } \\
\text { "Presentations" }\end{array}$ & No change \\
\hline $\begin{array}{c}\text { Advantages of } \\
\text { simulation activities }\end{array}$ & $\begin{array}{c}\text { "You can see actual } \\
\text { usage", "You can see } \\
\text { what happens", "Can still } \\
\text { see the issue" }\end{array}$ & $\begin{array}{c}\text { "Shows movement", } \\
\text { "Moving visual } \\
\text { component", "Manipulate } \\
\text { the solid models" }\end{array}$ & \\
\hline
\end{tabular}


The students were asked to relate their knowledge of the topics of threads, gears, and cams prior to using the simulations on a survey given on the first day of the research at each school. The responses to the questions that were similar to answers of "No prior knowledge", "Nothing", "I don't know anything about this", or "None" were coded as "None" in the data transcribing of student responses, shown in Table 4.

Table 4 - Student Prior Perceptions

\begin{tabular}{|c|c|c|c|c|c|}
\hline Themes & Threads & Cams & Gears & Total & \% \\
\hline None & 48 & 53 & 55 & 156 & 84 \\
\hline True understanding & 7 & 3 & 1 & 11 & 6 \\
\hline False misconceptions & 3 & 0 & 0 & 3 & 2 \\
\hline Incidental/Unrelated & 4 & 5 & 6 & 15 & 8 \\
\hline
\end{tabular}

Students answered approximately $15 \%$ of the time that they still did not understand the concepts of threads, cams and gears after completing the simulation activities. On the other hand, the majority of the students, $(61 \%)$ made accurate statements about the topics in the activities. A smaller percentage of student answers were either false or incidental/unrelated to the question asked. Table 5 shows the totals and percentages for the themes of none, true, false, and incidental/unrelated answers extracted from student surveys.

Table 5 - Student Post Perceptions

\begin{tabular}{|c|c|c|c|c|c|}
\hline Themes & Threads & Cams & Gears & Total & \% \\
\hline None & 5 & 10 & 9 & 24 & 15 \\
\hline True understanding & 34 & 36 & 27 & 97 & 61 \\
\hline False misconceptions & 8 & 0 & 4 & 12 & 8 \\
\hline Incidental/Unrelated & 10 & 6 & 9 & 25 & 16 \\
\hline
\end{tabular}

Each of these specific facts related about threads, cams and gears were coded from the student responses, and the highest amount of understanding related by the students in the threads unit is dealing with the content area of distance that a threaded component will travel in a certain number of revolutions. In the unit of cams the highest amount of understanding is dealing with the content area of the type of components necessary to keep the follower in contact with cam, and in the gear unit it is the content area of direction of gear trains.

When asked what worked well in the curriculum, the highest frequency of student responses in the treatment group (27\%) responded that the simulation software worked well in the activities in which they participated. In addition to what worked well, the students were also surveyed for what did not work well. Twenty-one percent of students responded negatively to the activity packets and 19\% the simulations. The students were then surveyed for their perceptions of what kind of improvements could be made to the curriculum, and the largest category of coded responses, $(25 \%)$ responded that the problem-based simulation activity packets could employ more clarity. Finally, approximately $85 \%$ of the students who participated in the treatment group responded that simulation is a beneficial tool because they could visualize difficult concepts. One 
student responded with the following quote: "It is a good way to see and visualize calculations as well as interferences, and possible problems and possible solutions as well". Approximately $23 \%$ of the students also responded that the benefit of the simulation activities is the ability to visualize the mechanisms in $3 \mathrm{D}$. This is similar to the teacher responses in the study.

\section{Conclusions}

According to the analysis results of the post-test scores the null hypothesis that there is no significant difference between the comparison and treatment group is false. Influencing the results are the number of students in the control group from School $\mathrm{C}$ who had little or no experience with drafting prior to the school year as compared to the larger number of students from Schools A and B with one year of experience in the treatment group. Limitations of the study include the primary researcher's involvement with the delivery of simulation activities and the differences that exist between the control and treatment groups that may have positively influenced the post test results of the treatment group. From the isolated sample in this research it can be concluded that the treatment group of students performed significantly better than the comparison group, and that simulation was perceived by students and teachers as a valuable tool to use in design and in the education of $\mathrm{CAD} /$ Drafting students.

Recommendations

After communicating the results of the study with the participant teachers and reflecting upon the experience, some recommendations for further utilization and research of this curriculum are as follows. The time constraints and requirement to have a control group of students not using the simulations in this study forced the teachers to use the simulation activities as a substitute for traditional activities rather than as a supplement to instruction. In order for the teachers to keep the two or three sections of students relatively on pace with each other they did not have the treatment groups do any traditional activities like drawings, or manipulation of physical parts; otherwise, they would have taken a considerably longer time to complete each topic.

As an ongoing process activities are being updated continuously by correcting any mistakes in the instructions and better packaging the materials using a CD ROM with interactive PowerPoint media to replace the paper handouts. This is in response to the student and teacher reactions to what they thought did not work well in the curricula. Also, NSF and MCC have funded three day workshops for teachers interested in learning more about operating the simulation software and utilizing the simulation activities providing participants with the simulation software to outfit a 25 station lab.

Implications

The strengths of the PBL simulation activities are their ability to grasp the interest of teachers and students because of the highly interactive element of the software. The teacher can modify the simulation models developed to accommodate specific needs of the learner. Once proficient with the simulation software, design engineering teacher educators can continue to add to the existing projects or create new applications designed around their course objectives. 
The PBL simulation activities still have their limitations because of the difficulty in implementing the activities in a self-paced classroom situation and the time required for students and teachers to master the complex software. Given adequate preparation, PBL

activities offer an advantage for technology educators that are in need of a tool that offers students the opportunity to test out solutions to problems in a simulated environment. The design simulation activities in this study offer many advantages to the user in visualizing results and being able to predict more accurately answers to problems.

References

1. Albanese, M. A. and Mitchell, S. (1993). Problem-based learning: a review of literature on its outcomes and implementation issues. Academic Medicine, 68, 52-81.

2. Allen, D. (1998). Bringing Problem-Based Learning to the Introductory Biology Classroom. In A. McNeal \& C. D'Avanzo (Eds.), Student Active Science (Ch. 15). from http://www.sanderscollege.com/lifesci/studact/chapters/ch15.html

3. Boud D. and Folletti, G., (Eds.). (1991). The challenge of problem-based learning in education for the professions. Sidney, Australia: Herdsa.

4. Dewey, John (1916). Democracy and Education: An introduction to the philosophy of education. New York: Addison-Wesley.

5. Hill, C. C. \& Semler, S. W. (2001). Simulation enhanced learning: Case studies in leadership development. LearningSim Books and Publications. from $\mathrm{http} / / / \mathrm{www}$. learningsim.com/content/sim_enhanced_learning.pdf

6. Johnson, D.W., Maruyama, G., Johnson, R.T., Nelson, D., \& Skon, L. (1981). Effects of cooperative, competitive and individualistic goal structures and achievement: A meta-analysis. Psychological Bulletin. 89, 47-62.

7. Kohlberg, L. (1979). Measuring moral judgment. Worcester, MA: Clark University Press.

8. Piaget, J. (1963). The moral judgement of the child. New York: The Free Press.

9. Swanson, R. A., \& Holton, E.F. (1999). Results: How to assess performance, learning and perceptions in organizations. San Francisco, CA: Berrett-Koehler Publishers, Inc. 